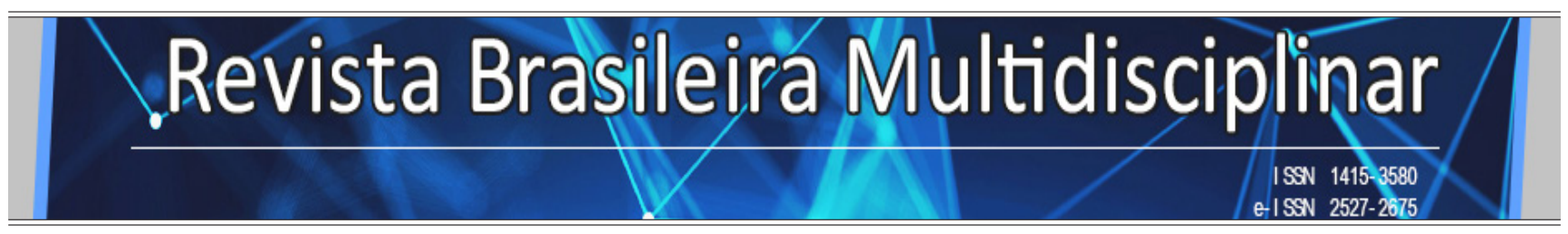

http://revistarebram.com/index.php/revistauniara

\title{
CONTEÚdos AMBIENTAIS NO ENSINO FUNDAMENTAL EM UMA ESCOLA MUNICIPAL DA CIDADE DE Araraquara, SP
}

\author{
Edna Lins dos Santos Pereira*; Maria Luca Ribeiro**; Flávia Cristina Sossae ${ }^{\star *}$ \\ ${ }^{*}$ Mestre pelo Programa de Pós-Graduação em Desenvolvimento Territorial e Meio Ambiente - UNIARA. \\ **Docentes no Programa de Pós-Graduação em Desenvolvimento Territorial e Meio Ambiente - UNIARA. \\ Brasil \\ *Autor para correspondência e-mail: ml.ribeiro@unesp.br
}

\section{Palavras-chave}

Educação Ambiental Ensino Fundamental Conteúdos Ambientais

\section{KEYWORDS}

Environmental Education

Elementary School

Environmental Contents

\begin{abstract}
RESUMO
O ambiente escolar é considerado como um espaço propício para a discussão das problemáticas ambientais, que podem ser abordadas de modo interdisciplinar, para que alcance amplitude nas diversas disciplinas que compõem a grade curricular. A pesquisa teve como objetivo avaliar como o tema educação ambiental (EA) vem sendo discutido nas disciplinas do Ensino Fundamental de uma escola do município de Araraquara, SP. Através de entrevistas abertas com as diretoras e aplicação de questionários semiestruturados à comunidade escolar foi constatado que as questões ambientais são apresentadas de forma fragmentada, algumas excluídas da realidade cotidiana dos estudantes e exclusivamente, inseridas nas disciplinas de Ciências e Geografia. Os temas mais abordados foram, plantio de árvores, aquecimento global, poluição, sustentabilidade, reflorestamento, preservação do meio ambiente, queimadas, água, natureza e reciclagem. Existe um descompasso e distanciamento quando se pensa o recorte ambiental no âmbito escolar, entre o que é discutido e o que é proposto.
\end{abstract}

\begin{abstract}
Environmental content in elementary school in a municipal school of the city of Araraquara, SP The school environment is considered as a space conducive to the discussion of environmental issues, which can be approached in an interdisciplinary way, so that it reaches breadth in the various disciplines that make up the curriculum. The objective of the research was to evaluate how environmental education (EA) is being discussed in the subjects of Elementary School in a school in the city of Araraquara, SP. Through open interviews with the directors and the application of semistructured questionnaires to the school community, it was verified that environmental issues are presented in a fragmented way, some excluded from the daily reality of students and exclusively inserted in the disciplines of Science and Geography. The most covered topics were tree planting, global warming, pollution, sustainability, reforestation, environment preservation, burning, water, nature and recycling. There is a mismatch and distancing when thinking about the environmental cut in school, between what is discussed and what is proposed.
\end{abstract}




\section{INTRODUÇão}

Problemas ambientais atualmente presentes em nossa sociedade, como: consumismo excessivo e consequente geração intensiva de resíduos; aquecimento global; destruição e degradação de ecossistemas naturais e escassez de recursos essenciais à manutenção da vida devido às atividades humanas, estimulados pelo desenvolvimento cultural e tecnológico exploratório demandam soluções não somente governamentais, mas também de engajamento e comprometimento da população (OLIVEIRA, 2007; FERRARI e ZANCUL, 2008; ABREU et al.; CAMPOS e AGUILAR, 2008; FERREIRA, 2011; LOPES, 2013; GARRIDO e MEIRELLES, 2014). Nessa perspectiva, a educação ambiental (EA) surge oficialmente durante o encontro de Belgrado, em 1975 na Iugoslávia e, em 1977 em Geórgia, a fim de fornecer aos grupos sociais consciência e despertar-lhes sensibilidade a respeito das questões ambientais, bem como fornecer-lhes aptidões necessárias para que os mesmos possam buscar soluções, do ponto de vista ecológico, político, social e educativo (REIGOTA, 2004; FARIAS e CARVALHO, 2007; LOPES, 2013; BALDIVIA et al., 2014,).

Segundo a literatura, é no ambiente escolar que tais problemáticas, e outras mais, podem ser trabalhadas de maneira interdisciplinar, durante a formação crítica, reflexiva e participativa dos alunos, do ponto de vista político (OLIVEIRA, 2007; ABREU et al., 2008; LOUREIRO, 2009; CHADDAD et al., 2011; BALDIVIA et al., 2014, tradução nossa; GARRIDO e MEIRELLES, 2014). Neste sentido, a Lei de Diretrizes e Bases da Educação Brasileira, de 20 de dezembro de 1996 (Lei 9.394/96), aponta a necessidade de uma formação mais ampla do estudante da escola básica e sugere que a compreensão do ambiente natural instigue reflexões sobre as questões ambientais (FERRARI; ZANCUL, 2008). De maneira colaborativa, em 1998, houve a incorporação de conteúdos ambientais nos sistemas de ensino através dos Parâmetros Curriculares Nacionais (PCNs), os quais ressaltam a importância das questões ambientais para o futuro da humanidade, relatando que esta relação é extremamente dependente da maneira com que o ser humano se apropria dos recursos disponíveis: "visa contribuir para a formação de cidadãos conscientes, aptos a decidirem e atuarem na realidade socioambiental de um modo comprometido com a vida, com o bem-estar de cada um e da sociedade local e global" (BRASIL, 2007). Assim, a criação dos PCNs serviu para nortear professores a trabalharem a Educação Ambiental (EA) no ensino escolar, atribuindo-se à educação básica o exercício para a cidadania e propondo-se um currículo vinculado à vida dos estudantes, contextualizado e fundamentado na interdisciplinaridade. Dessa forma, as temáticas relacionadas à cidadania, as quais incluem meio ambiente, diversidade cultural, entre outros, estão previstas de forma transversal, em todas as disciplinas (FARIAS; CARVALHO, 2007; BRASIL, 1999). Ainda, Iared e Oliveira (2011) concluem em seu trabalho, o qual consistiu em ouvir professoras do ensino fundamental sobre o ponto de vista da educação ambiental e perspectivas pedagógicas, que muitos educadores ambientais ressaltam a importância da transversalidade da educação ambiental se estender aos outros componentes sociais exteriores ao âmbito escolar, como: áreas da saúde, transporte, comunicação e cultura. Entretanto, apesar da importância de se trabalhar EA de modo interdisciplinar, é evidente a resistência e dificuldade existente para se integrar disciplinas, bem como tratar as questões ambientais com sua devida importância, não as isolando da realidade das pessoas, como geralmente ocorre, ou as tratando como um impedimento ao desenvolvimento tecnológico e social, em que se têm geralmente apenas a realização de atividades pontuais em datas comemorativas (ABREU; CAMPOS; AGUILAR, 2008; LOUREIRO, 2009; IARED; OLIVEIRA, 2011).

Vários trabalhos vêm sendo publicados na literatura a fim de investigar como a EA ocorre nas escolas de ensino fundamental (IARED; OLIVEIRA, 2011). Neste contexto, Baldivia e colaboradores (2014) desenvolveram uma pesquisa participativa em uma escola municipal de Dourados (MS), em que os estudantes, juntamente com os pesquisadores, criaram um jardim voltado à alimentação escolar com o 
reaproveitamento de garrafas PET; Lopes (2013) analisou o modo como a EA é desenvolvida entre o sexto e nono ano do ensino fundamental em uma escola da localidade de Araraquara, SP; A fim de verificar como EA é abordada nos livros didáticos de Geografia dos ensinos fundamental e médio, Meneguzzo e Meneguzzo (2012) desenvolveram seu estudo em escolas públicas do estado de Paraná; Chaddad e colaboradores (2011) realizaram um estudo participativo na formação de alunos do sexto a nono ano do ensino fundamental, visando estudar a formação de cidadãos participativos, conscientes de sua integração com a natureza e capazes de transformar suas realidades; buscando-se constatar se a EA proposta em políticas públicas, documentos do MEC e pela Secretaria de Educação e Meio Ambiente vêm sendo aplicadas na educação de maneira efetiva, Ferreira (2011) desenvolveu seu estudo em escolas públicas da rede do estado de São Paulo; Cavalcanti Neto e Amaral (2011) avaliaram as diferentes estratégias metodológicas utilizadas por professores do ensino fundamental para o ensino de EA em escolas públicas de Escada (PE); Ferrari e Zancul (2008) analisaram as propostas em EA presentes nos projetos políticos pedagógicos (PPP) de escolas da cidade de Araraquara (SP) verificando se os mesmos são complementados por experiência dos alunos e condizem com suas realidades; Costa, Monteiro e Costa (2008) analisaram conteúdos de EA existentes nos projetos de duas escolas de ensino fundamental, sendo uma pública e uma particular, e relacionaram como essas práticas são desenvolvidas nas mesmas; Saraiva, Nascimento e Costa (2008) investigaram se escolas públicas de João Câmara, Rio Grande do Norte, estão cumprindo com o determinado pelos PCN referente a obrigatoriedade de práticas permanentes sobre EA nos currículos escolares.

Diante do exposto, o presente estudo objetivou analisar propostas referentes à EA desenvolvidas pelos profissionais da área de educação em disciplinas do sexto ao nono ano do ensino fundamental e relacionar o entendimento dos respectivos estudantes sobre tais conhecimentos em uma escola de Araraquara, município da região central do estado de São Paulo.

\section{Metodologia}

\section{ESPAÇO DA PESQUisa}

A escola em estudo, denominada A, está situada em um bairro periférico na cidade de Araraquara, região central do estado de São Paulo. Atendendo cerca de 1080 alunos do primeiro ao nono ano do ensino básico, sua estrutura administrativa é composta de direção, vice direção, direção administrativa, quatro coordenadores, uma assistente educacional pedagógica, uma atendente educacional especializada, uma equipe de setenta e cinco professores, onze agentes educacionais e uma equipe funcional (secretaria, cozinha e terceirizados). No que diz respeito à estrutura física da instituição, a mesma possui dois laboratórios de informática, um laboratório de ciências, uma brinquedoteca, uma biblioteca e uma quadra coberta.

\section{ColetA dos DADOS}

Este trabalho teve como base a pesquisa qualitativa, definido por Neves, (1996) e os dados foram coletados por meio de aplicação de questionários semiestruturados aos coordenadores (4), professores (19) e estudantes do sexto ao nono ano do ensino fundamental (70), durante ano letivo de 2012, sendo que os mesmos foram informados e esclarecidos que ao participarem da pesquisa não sofrerão danos físico, psíquico, moral, intelectual, social, cultural ou espiritual, e ainda, com o intuito de assegurar a confidencialidade e a privacidade de suas identidades e das informações seus nomes não foram mencionados. Posteriormente, os participantes que concordaram em participar da pesquisa assinaram o Termo de Consentimento Livre e Esclarecido (TCLE), onde consta a natureza da pesquisa, seus objetivos, métodos, benefícios previstos, potenciais riscos e o incômodo que esta possa acarretar. 
Nos questionários direcionados aos coordenadores e professores procurou-se caracterizar as ações da escola em relação ao tema ambiental abordando: projetos desenvolvidos em parceria ou não, disciplinas envolvidas nestes projetos, capacitação oferecida aos professores, dados ambientais do material do SESI, facilidades e dificuldades encontradas para desenvolver as atividades envolvendo temas ambientais e sugestões que a médio e longo prazo poderiam contribuir para ações na área de educação ambiental. Ainda, no questionário dos professores foram acrescidas questões sobre os temas ambientais inseridos previamente no PPP, no projeto e ensino, no Plano de Trabalho Docente ou sugerido pela Secretaria da Educação, recursos adotados para trabalhar meio ambiente, participação e interesse dos alunos.

O questionário destinado aos estudantes compreendeu: identificação dos discentes, disciplinas que abordam EA e participação em atividades sobre o meio ambiente. Foi selecionada uma turma para cada ano estudado, totalizando quatro salas, das quais participaram 13 alunos do sexto ano, 21 do sétimo, 15 do oitavo e 21 do nono (70 alunos no total).

Os instrumentos de coleta de dados foram elaborados segundo os descritos na literatura (RUSCHMANN, 2007; SILVA; GRILLO, 2008; ABREU; CAMPOS; AGUILAR, 2008). Para validação dos questionários foi realizado um teste piloto com estudantes e professores em outra instituição de ensino.

Os dados foram organizados em categorias de acordo com trabalho desenvolvido por Pereira, et al. (2009) tendo como foco estabelecer similaridades e diferenças no que se refere à análise dos conteúdos ambientais dos questionários aplicados à direção, coordenadores, professores e alunos, para gerar um panorama e elaborar a categorização.

\section{Resultados e Discussão}

\section{Perfil dos CoOrdenadores e professores}

Um perfil profissional foi traçado para os quatro coordenadores e 19 professores os quais participaram da pesquisa, visando conhecer melhor suas formações e compreender suas experiências, para relacioná-las ao ensino transversal em EA. Dentre os docentes estudados, 4 lecionam Língua Portuguesa, 3 Matemática, 2 Ciências, 2 Geografia, 2 História, 2 Artes, 1 Inglês e 3 Educação Física. Os dados referentes ao perfil destes formadores foram sistematizados na Tabela 1.

Tabela 1 - Perfil profissional dos coordenadores e docentes da escola em estudo no município de Araraquara - SP.

\begin{tabular}{l|c|c|c}
\hline Perfil profissional & & Coordenadores & Docentes \\
\hline Formação & Pós graduação & $75 \%$ & $47 \%$ \\
\hline \multirow{2}{*}{ Tempo de atuação } & 0 a 8 anos & $100 \%$ & $37 \%$ \\
\cline { 2 - 4 } & 8 a 16 anos & - & $11 \%$ \\
\cline { 2 - 4 } & 16 a 24 anos & - & $21 \%$ \\
\cline { 2 - 4 } & 24 a 32 anos & - & $31 \%$ \\
\hline
\end{tabular}

Fonte: Elaboração Própria.

Pode se observar que $47 \%$ dos professores, $75 \%$ dos coordenadores possuem pós-graduação lato sensu. Com relação ao tempo de atuação na docência apenas um está há quatro anos na coordenação e os demais entre um e um ano e meio. Já entre os professores há uma variação de cerca de 20 anos, na atuação de docência, comprovando que a maioria tem uma larga experiência no trabalho docente, apenas 
dois professores com dois anos de docência, podem ser considerados iniciantes na profissão.

O professor desempenha um papel como mediador no processo ensino-aprendizagem e, a partir dos dados, podemos ressaltar a importância da formação docente de acordo com a área específica de conhecimento, facilitando na atuação e na execução de atividades que conscientizam valores ambientais voltadas para a perspectiva interdisciplinar em Educação Ambiental (RUSCHMANN, 2007)

\section{Conteúdos DE EA TRABALHAdOS NA ESCOLA SEGUNDO COORDENADORES}

Para caracterizar as ações da escola em relação às questões ambientais, foram abordados nos questionários: a) projetos desenvolvidos em parceria ou não, bem como disciplinas envolvidas; b) capacitação oferecida aos docentes; c) conteúdos ambientais fornecidos pelo material didático adotado na escola (material do SESI); d) facilidades e dificuldades encontradas para desenvolver atividades sobre EA; e) sugestões para contribuir com o desenvolvimento do tema EA a médio ou longo prazo.

Dois projetos foram desenvolvidos na escola $\mathrm{A}$, sobre os temas preservação ambiental e consumo racional de água e energia, em que participaram das atividades somente as disciplinas de Ciências e Língua Portuguesa em 2012. Já, em relação à capacitação oferecida aos docentes sobre EA, os coordenadores informaram que em 2011 houve um encontro na Secretaria Municipal de Educação (SME) sobre temas ambientais, do qual os docentes não participaram, mas os coordenadores estiveram presentes. Ainda, em 2012, em parceria com a Secretaria Municipal do Meio Ambiente, a escola trabalhou a conscientização sobre o reflorestamento do Córrego Água Branca, o qual se localiza no entorno da escola A, com o oferecimento de palestras para professores na Atividade de Trabalho do Professor Coletivo (ATPC).

Quando questionados sobre o material didático adotado pela escola, dois coordenadores (dos ciclos II e III) afirmaram que o tema EA é contemplado somente nas disciplinas de Geografia, Ciências e Língua Portuguesa, ao passo que o coordenador do ciclo I mencionou ainda a disciplina História, e o quarto coordenador, também responsável pelo ciclo II, acrescentou Matemática e Artes. Tal fato sugere diferentes percepções dos coordenadores sobre os conteúdos referentes à EA.

Quanto às facilidades e dificuldades para se desenvolver temas ambientais na escola, os coordenadores apontaram basicamente a falta de envolvimento de alguns docentes e da gestão escolar, a falta de espaço para realizar atividades diferenciadas em EA, embora os estudantes demonstrassem interesse no assunto. Várias sugestões para contribuir com as ações em temas ambientais apontadas pelos coordenadores envolviam consolidar parcerias com a Secretaria Municipal do Meio Ambiente no desenvolvimento do projeto Revitalização do Córrego Água Branca; capacitação mais efetiva dos professores; conscientização dos professores, estudantes e comunidade; planejamento e gestão de projetos ambientais.

Essas questões também foram apontadas por Ferreira (2009) e Ruschamnn (2007) que mencionam o despreparo dos professores, a falta de infraestrutura e incentivo na escola e ainda, salas muito numerosas.

\section{Conteúdos de EA TRABAlHAdos NA ESCOLA SEgundo PROFESSORES}

As questões propostas para os professores sobre os conteúdos em EA, obedeceram a uma abordagem similar às dos coordenadores, acrescidas de especificações do trabalho docente: a) temas ambientais inseridos previamente no Projeto Político Pedagógico (PPP), no projeto de ensino, no Plano de Trabalho Docente ou sugerido pela Secretaria da Educação; b) recursos adotados para trabalhar meio ambiente; c) participação e interesse dos estudantes.

Os professores informaram que a escola desenvolveu entre os anos de 2009 e 2012 projetos ambientais abordando preservação ambiental, consumo racional de água e energia, reciclagem de óleo de cozinha, reflorestamento da unidade escolar, reflorestamento do Córrego Água Branca, cuidado e tratamento do 
lixo orgânico para produção de adubo, arborização da escola. Inclusive foi apontado que, entre o período de 2010 e 2012, houve aumento da participação dos professores nos projetos que envolvem temas ambientais, o que pode ser consequência das palestras realizadas pela Secretaria do Meio Ambiente. Embora os professores tenham assinalado participação em projetos em EA, a participação ativa sempre foi, de fato, dos professores de Ciências, devido ao conteúdo da disciplina abordar temas ambientais. No que diz respeito às demais disciplinas, as atividades são desenvolvidas somente de forma pontual em datas comemorativas. Sobre a capacitação dos professores para trabalhar EA, a maioria dos docentes informou que a mesma é dirigida para os professores de Ciências. Entretanto, mencionaram ainda, que abordam temas ambientais em algum conteúdo específico de sua disciplina.

Quando questionados em quais documentos estão inseridos os temas ambientais, os professores indicaram que estão inclusos no Plano de Trabalho Docente, e seis assinalaram a inclusão no PPP da escola. Como o Plano de Trabalho Docente é avaliado pelos coordenadores em cada bimestre, se os temas ambientais forem contemplados neste documento, o professor deve trabalhá-lo em suas aulas. Isso aponta para um desacerto entre o que de fato está descrito nos documentos da escola, o que afirmam os professores e coordenadores e o que é efetivamente praticado na escola, pois, o PPP da escola estudada contempla uma proposta pedagógica sobre EA sob a forma de projeto de Preservação do Meio Ambiente, cujo principal objetivo é a conscientização dos estudantes, de forma que as atividades referentes não estão articuladas aos conteúdos curriculares, conforme proposto pelo PCN. Como evidenciado por Lopes (2013), projetos e complexos temáticos são desarticulados dos conteúdos curriculares específicos, de forma que a abordagem ambiental ocorre somente quando temas relacionados estão presentes nos materiais didáticos utilizados pelos docentes.

Quanto aos recursos utilizados em aula para trabalhar EA, várias estratégias metodológicas são utilizadas pelos professores (Figura 1), entretanto observa-se que a aula expositiva, apesar de não ser a forma mais eficiente de se desenvolver valores, atitudes e construir conhecimentos de forma participativa, como preconizam os princípios da EA, ainda é o recurso didático mais utilizado.

Figura 1 - Recursos didáticos utilizados pelos professores da escola A no município de Araraquara - SP.

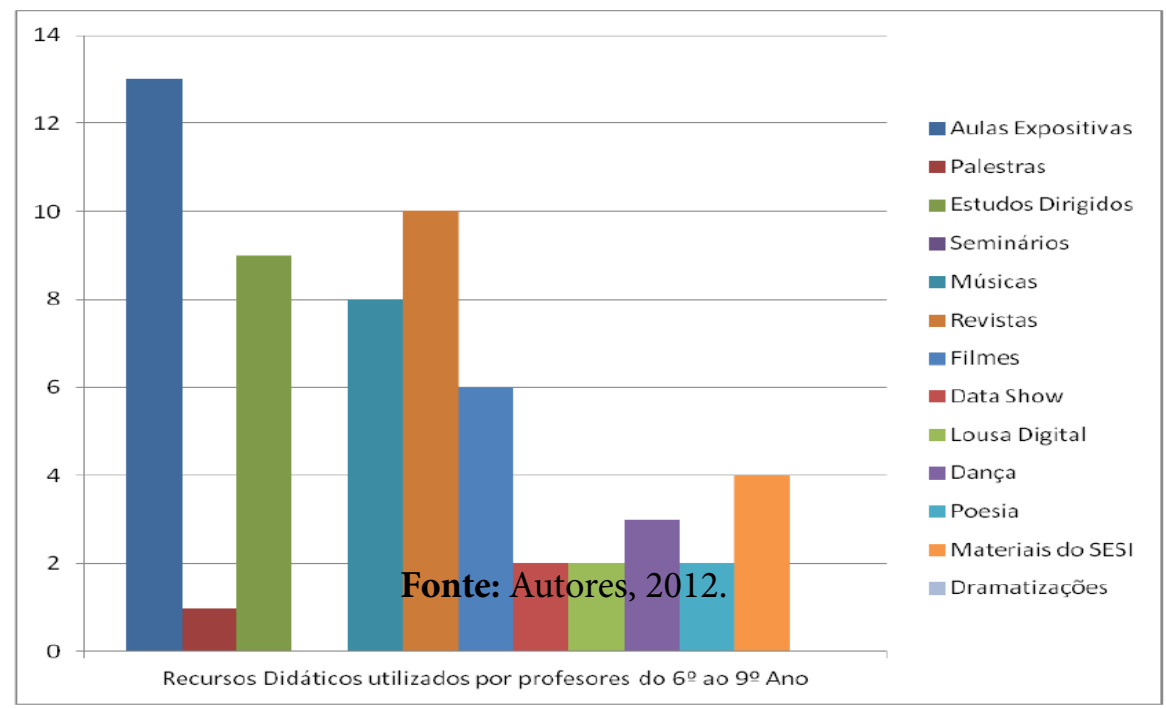

Fonte: Autores, 2019. 
É importante ressaltar que o material didático adotado pela escola, o material do SESI, não foi apontado como um recurso relevante para se trabalhar as questões ambientais. Os professores de Geografia, Ciências, História, Artes e Língua Portuguesa afirmam que os conteúdos presentes no material do SESI abordam o tema ambiental; em contrapartida, os docentes de Educação Física, Matemática, Inglês, História e Língua Portuguesa apontam que não há temas ambientais abordados no material. Os conflitos podem ser observados quando se pensa o recorte ambiental no âmbito escolar: diferentes olhares e conceitos, sugerindo a necessidade de um trabalho mais concreto e interdisciplinar, de maneira que os sistemas educativos necessitam de reformulações urgentes em suas propostas curriculares, a fim de tornarem-se mais aptos para responder os desafios sociais, econômicos, culturais e profissionais que se tornem presentes (BIGLIARDI; CRUZ, 2008). Ainda, segundos os professores, alguns aspectos positivos em relação a este material são que o mesmo, apresenta textos atuais, jogos e brincadeiras que facilitam o desenvolvimento das atividades. Da mesma forma, os aspectos negativos destacados pelos docentes foram: "deficiência na sequência de informações", "poucos recursos para fixar os conceitos e práticas", "é muito repetitivo", "não são apropriados para o ano de ciclo", "fora da realidade dos alunos", "textos longos e desinteressantes", "não focaliza os aspectos gramaticais", "grandes dificuldades no vocabulário", "mistura conteúdos no mesmo capitulo", "é um material a mais para se trabalhar", "textos complexos", "sem conteúdos apenas ideias", "atividade que exige pesquisa e não são todos que possuem recursos para isso", "falta organização" $e$ "impõem maneiras de atuação profissional sem conhecer a realidade em que trabalhamos". O pouco tempo de implantação do material do SESI e a falta de capacitação oferecida aos professores sugere as contradições observadas neste estudo.

Os professores mencionaram que os livros do material do SESI apresentam conteúdos ambientais nas disciplinas de Geografia e Ciências em todos os anos do ensino fundamental analisado e ainda, que nas disciplinas de Inglês e Educação Física não possuem nenhum tópico de conteúdo ambiental. Quanto à Língua Portuguesa, Matemática, História e Artes, os conteúdos são apresentados de forma fragmentada sem sequência lógica e articulação com as demais disciplinas. Tais dados são similares aos descritos na literatura para o ensino fundamental (FERREIRA, 2011; MENEGUZZO; MENEGUZZO, 2012; SULEIMAN; ZANCUL, 2012). Ainda, sobre os materiais didáticos referentes ao ensino fundamental, Bonotto e Semprebone (2010) desenvolveram em seu estudo uma análise crítica sobre os conteúdos ambientais de livros didáticos de Ciências Naturais e constataram a presença da visão antropocêntrica em alguns materiais, de maneira a induzir os estudantes a acreditarem na figura humana como dona do ambiente e os demais organismos e recursos são valorizados apenas por suas serventias à espécie humana, o que contribui para uma visão fragmentada e isolada entre meio ambiente e suas vidas por parte dos estudantes Ressalta-se a preocupação com tais informações descritas acima, uma vez que: "os livros didáticos ainda se constituem um dos instrumentos-base utilizados pelos professores, no processo ensino aprendizagem" (MENEGUZZO; MENEGUZZO, 2012, p.82).

A avaliação dos professores sobre a participação dos estudantes em temas ambientais indica problemas e contradições entre as percepções de cada professor, como demonstram as afirmações: "participam de forma efetiva"; "a participação dos alunos é unânime e os mesmos se interessam pelas questões, pois se sentem parte deste ambiente e responsáveis por ele"; "interesse no momento, mas devemos intensificar o trabalho para uma melhor assimilação do tema meio ambiente para o futuro"; "envolvem bastante principalmente quando as questões estão atreladas a localidade, ou seja, quando se sentem próximos a estas questões"; "participação boa, mas infelizmente as ações não são contínuas"; "na parte teórica há uma boa interação, mas na prática demonstram poucas atitudes positivas"; "apresentam colaboração momentânea, porque foram cobrados". Ainda, há relatos de que os estudantes não demonstram interesse em preservar 
o ambiente escolar, pois: "não possuem interesse”; "jogam lixo no chão (papéis de bala, chicletes e folhas de cadernos)"; da mesma forma que há relatos que afirmam o contrário: "tem consciência da sua importância de seu papel como cidadão na manutenção do ambiente"; "é feita a preservação e cuidados com as plantas, e a reciclagem no ambiente escolar é feita diariamente"; "pelo menos quando o assunto é abordado, demonstram preocupação e interesse em colaborar"; "eles já entenderam que é patrimônio público e é importante para todos".

Em um estudo desenvolvido por Cavalcanti Neto e Amaral (2011) em escolas públicas do Município de Escada, PE, nota-se que, apesar das grandes dificuldades em se incentivar uma visão crítica ambiental aos estudantes, como romper com a concepção limitante naturalista de meio ambiente, são inúmeras as possibilidades para o desenvolvimento desta perspectiva, dada a diversidade de espaços didáticos que podem ser utilizados para tais discussões, como o biológico, químico, físico, social, histórico, cultural e político. Assim, os autores sugerem a extrapolação das abordagens propostas pelos livros didáticos e a valorização dos diálogos e saberes entre estudantes e professores, possibilitando a formação de sujeitos críticos, inclusive na formação continuada de professores, promovendo reflexões quanto às práticas docentes sobre o tema.

As sugestões dos professores que poderiam contribuir para que as práticas pedagógicas em EA fossem valorizadas na escola A incluem: conscientização dos gestores da escola em relação à EA, palestras, capacitação dos professores, cursos para os estudantes em horários contrários aos de aula, práticas para que os alunos vivenciem os problemas e prováveis soluções para os atuais problemas ambientais, excursões ecológicas, material específico incluído no cotidiano do aluno, especialista da área trabalhando diretamente com os alunos, mini lixeiras ambientais na sala, conscientização do uso de cadernos e folhas, projetos nos bairros com a participação da comunidade, realização de semanas voltadas ao meio ambiente, trabalho interdisciplinar em prol das questões ambientais. Tais afirmações ressaltam a necessidade de modificações das propostas metodológicas de ensino, visando a construção de cidadãos solidários, conscientes de suas responsabilidades para com o presente e futuro do planeta, conforme indicado por Bigliardi e Cruz (2008) e Loureiro (2009).

\section{CONTEÚdOS DE EA TRABALHADOS NA ESCOLA SEGUNDO OS ESTUDANTES}

A participação não obrigatória em atividades voltadas para o tema meio ambiente foi crescente entre o período de 2008 e 2012 na escola, devido às ações que a Secretaria do Meio Ambiente exerceu na instituição. Dentre os diferentes anos, teve participação primária nessas atividades alunos do sétimo ano (16 alunos), seguidos do nono ano (14 alunos) e por fim os do sexto ( 9 alunos).

Com relação aos dados relacionados ao meio ambiente, as respostas dos estudantes indicaram que o plantio de árvores e as apresentações no Dia do Meio Ambiente (dança, música, poesia e cartazes) são as atividades que eles demonstraram maior interesse e participação.

Quando questionados quanto aos temas que foram trabalhados sobre meio ambiente pelos professores, os discentes descreveram aquecimento global, plantio de árvores, poluição, sustentabilidade, reflorestamento, preservação do meio ambiente, queimadas, água, natureza e reciclagem.

As disciplinas que mais discutem EA, segundo os discentes, são Ciências, Geografia e Artes (Figura 2). A percepção desses estudantes se assemelha aos resultados descritos na literatura por diversos autores (SARAIVA; NASCIMENTO; COSTA, 2008; KLIEMANN, 2008; ABREU; CAMPOS; AGUILAR, 2008; LOUREIRO, 2009; FERREIRA, 2011). No caso de estudo, ressalta-se que o material SESI, adotado pela instituição, contempla temas ambientais apenas nestas disciplinas. 
Figura 2 - Disciplinas que abordam o tema ambiental segundos os estudantes da escola A no município de Araraquara - SP.

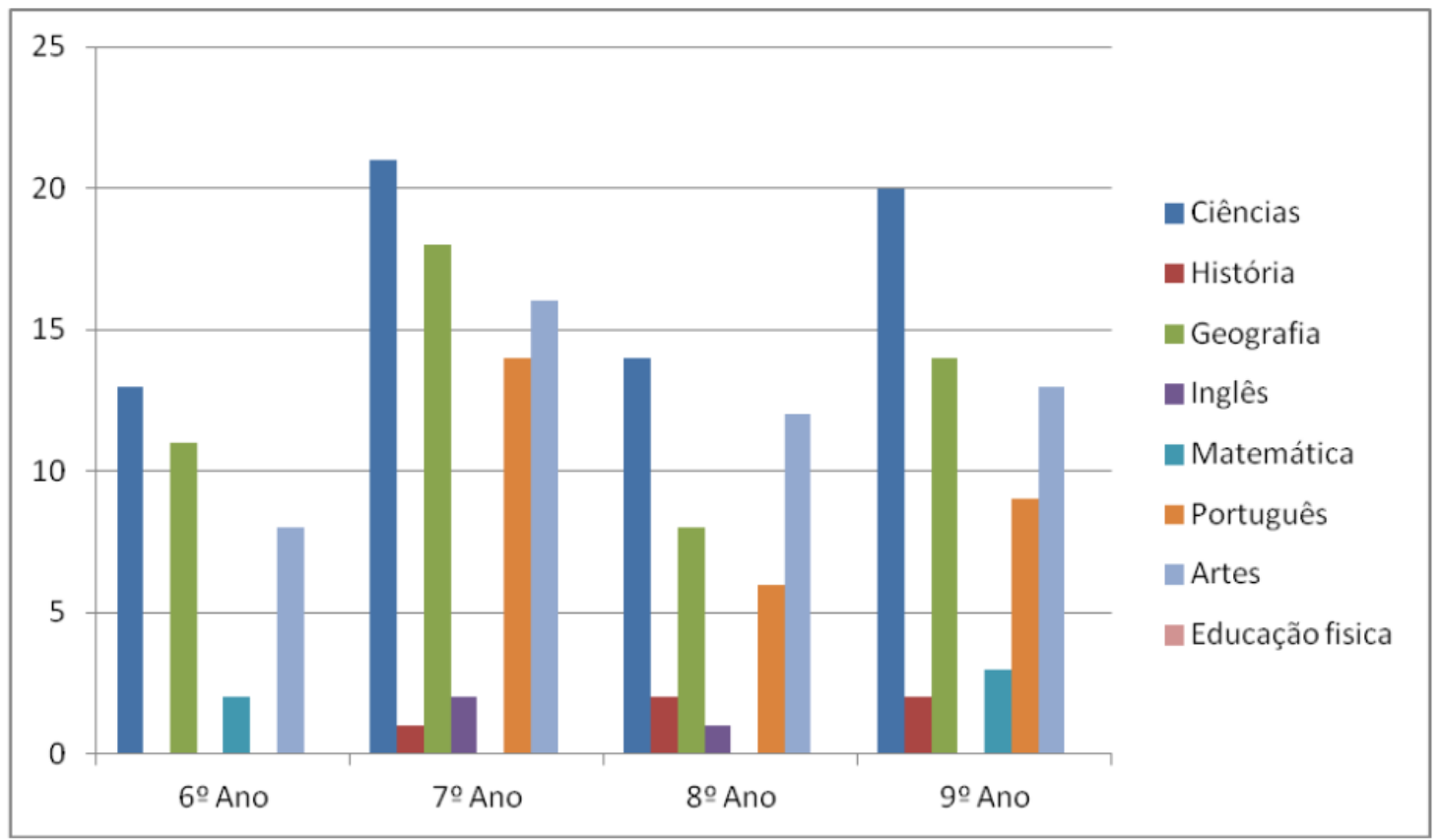

Fonte: Autores, 2012.

O entendimento da maioria dos estudantes sobre meio ambiente (79\%) pode ser representado por "um lugar importante para viver onde há animais, rios e que deve ser preservado para as gerações futuras e que não devemos poluir", e $21 \%$ não responderam. Adicionalmente, os estudantes foram questionados sobre o que fazem na escola e em suas casas para melhorar o meio ambiente. Entre as respostas, obtevese, independentemente do ano analisado "plantar árvores', "economizar água e energia”, "jogar lixo no lixo", "reciclar", refletindo as ações que foram desenvolvidas, mas que realmente não são efetuadas. A análise geral dos resultados dos questionários dos estudantes aponta similaridade das respostas e indica que os conceitos sobre meio ambiente são ainda muito primários. Tal fato também é verificado por Garrido e Meirelles (2014) ao analisarem a percepção de estudantes do primeiro ao quinto ano do ensino fundamental de uma escola municipal de Duque de Caxias, RJ. A concepção de conceitos primários refere-se às respostas dadas pelos estudantes como uma visão somente para o problema enfrentado no dia a dia. Esses resultados são corroborados por dados semelhantes encontrados na literatura, em que a visão naturalista dos estudantes em relação ao meio ambiente ainda é predominante em várias pesquisas (GARRIDO; MEIRELLES, 2014; PEREIRA; MANSUR; ALVES, 2014), o que indica que a educação ambiental vem sendo trabalhada de forma superficial, de maneira que os discentes não se percebem como parte do meio ambiente, enxergando-o como algo isolado de seus cotidianos e de suas realidades, não se incluindo como seres ativos e responsáveis pelas mudanças positivas ou negativas que o ambiente está sujeito. Essa visão, ainda está ligada ao paradigma cartesiano, que perdurou por décadas e moldou gerações, considerando o ser humano como usuário e não integrante da natureza, a qual precisa ser desmistificada e derrubada para garantir a saúde dos ambientes naturais e, consequentemente, das populações dos seres vivos, dentre eles, os seres humanos (IARED; OLIVEIRA, 2011; PEREIRA; MANSUR; ALVES, 2014). 


\section{CONCLUSÃo}

A existência de um grande descompasso e distanciamento de várias naturezas, quando se pensa o recorte ambiental no espaço escolar entre o que é proposto e o que de fato é efetuado e realizado, ressalta a necessidade de se revisar as propostas metodológicas e a participação efetiva da gestão escolar e do corpo docente na elaboração do PPP, o qual permitiria vincular teoria e prática, ao longo do ano letivo.

O relevante interesse dos estudantes nas atividades de EA, reflexo das ações realizadas na escola, demonstraram noção de lugar para se viver, de cuidado e de preocupação com as gerações futuras dos discentes.

A formação ambiental na área do conhecimento dos professores e a articulação de projetos integrando diversas disciplinas poderiam trazer grandes ganhos á EA realizada nesta e em outras escolas.

A educação escolar, por si só, não tem obrigação de resolver os problemas ambientais, porque a educação ambiental tem como função a transformação e, para isso, ela deve, primeiramente, favorecer a formação de profissionais.

\section{REFERÊNCIAS}

ABREU, D; G.; CAMPOS, M. A. M.; AGUILAR, M. B. R. Educação ambiental nas escolas da região de Ribeirão Preto (SP): concepções orientadoras da prática docente e reflexões sobre a formação inicial de professores de química. Química Nova, v. 31, n. 3, p. 688-693, 2008.

BALDIVIA, D; S. Mobile garden: seeding the knowledge to harvest the sustainability in the school.. Journal of Sustainability Development, v. 7, n. 6, p, 175-181, 2014.

BIGLIARDI, R. V.; CRUZ, R. G. Currículo escolar, pensamento crítico e educação ambiental. Revista Eletrônica do Mestrado em Educação Ambiental, v. 21, p. 332-340, 2008.

BONOTTO, D. M. B.; SEMPREBONE, A. Educação ambiental e educação em valores em livros didáticos de Ciências Naturais. Ciência \& Educação, v. 16, n. 1, p. 131-148, 2010.

BRANDÃO, C. R. Pesquisa participativa. In: FERRARO JUNIOR, L. A. Encontro e caminhos: formação de educadoras (es) ambientais e coletivos educadores. 2. ed. Brasília: MMA, 2005.

BRASIL. Lei no. 9795, de 27 de abril de 1999: dispõe sobre a educação ambiental, institui a Política Nacional de Educação Ambiental e dá outras providências. Brasília, DF: Diário Oficial da União, 28 abr. 1999. Disponível em: <http://www.planalto.gov.br/ccivil /Leis /L9795.htm>. Acessos em: 29 maio 2018.

BRASIL. Secretaria de Educação Fundamental. Parâmetros Curriculares Nacionais: meio ambiente e saúde. Brasília, 1997.

CAVALCANTI NETO, A. L. G.; AMARAL, E. M. R. do. Ensino de ciências e educação ambiental no nível fundamental: análise de algumas estratégias didáticas. Ciência \& Educação, v. 17, n. 1, p. 129-144, 2011.

CHADDAD, F. R. et al. Educação ambiental de corpo e alma através de metodologias participativas junto a alunos do $6^{\circ}$ ao $9^{\circ}$ anos do ensino fundamental. Revista Uniara, v. 14, n. 1, p. 39-51, 2011. 
COSTA, M. F. B.; MONTEIRO, S. C. F.; COSTA, M. A. F. Projeto de educação ambiental no ensino fundamental: bases para práticas pedagógicas. Revista Eletrônica do Mestrado em Educação Ambiental, v. 21, p. 133-144, 2008.

FARIAS, C. R. O.; CARVALHO, W. L. P. O direito ambiental na sala de aula: significados de uma prática educativa no ensino médio. Ciência \& Educação, v. 13, n. 2, p. 157-174, 2007.

Ferrari, A. H. Educação ambiental em escolas de ensino fundamental da rede municipal de Araraquara: do projeto político-pedagógico à sala de aula. 2009. 221 f. Dissertação (Mestrado em Educação Escolar) - Universidade Estadual Paulista, Faculdade de Ciências e Letras, Araraquara, 2009.

FERRARI, A. H.; ZANCUL, M. C. S. Educação ambiental: do projeto político-pedagógico à sala de aula. Educação em Revista, v. 9, n. 1, p. 19-34, jan.-jun. 2008.

FERREIRA, C. E. A. O meio ambiente na prática de escolas públicas da rede estadual do estado de São Paulo: intenções e possibilidades. 2011. 177 f. Tese (Doutorado em Educação) - Faculdade de Educação, Universidade de São Paulo, 2011.

GARRIDO, L. S.; MEIRELLES, R. M. S. Percepção sobre meio ambiente por alunos das séries iniciais do ensino fundamental: considerações à luz de Marx e de Paulo Freire. Ciência \& Educação, Bauru, v. 20, n. 3, p. 671-685, 2014.

IARED, V. G.; OLIVEIRA, H. T. de. Concepções de educação ambiental e perspectivas pedagógicas de professoras do ensino fundamental. Educação em Revista, Belo Horizonte, v. 27, n. 2, p. 95-122, ago. 2011.

KLIEMANN, M.T. P. A educação ambiental na práxis pedagógica de professores de educação infantil e do ensino fundamental. 2008. Dissertação (Mestrado em Educação) - Universidade do Oeste Paulista, Presidente Prudente, 2008.

LOPES, T. M. A educação ambiental nos anos finais do ensino fundamental em uma escola de campo: um estudo sobre as práticas escolares. 2013. 147 f. Dissertação (Mestrado em Educação Escolar) - Universidade Estadual Paulista, Faculdade de Ciências e Letras, Araraquara, 2013.

LOUREIRO, D.G. Educação ambiental no ensino fundamental: um estudo da prática pedagógica em uma escola municipal de Palmas - TO. 2009. 91 f. Dissertação (Mestrado em Educação) - Universidade de Brasília, Brasília, 2009.

MENEGUZZO, P. M.; MENEGUZZO, I. S. A educação ambiental nos livros didáticos de geografia do ensino fundamental e médio utilizados nas escolas públicas do Paraná. Revista Eletrônica do Mestrado em Educação Ambiental, v. 28, p. 72-84, 2012.

OLIVEIRA, M. V. Educação ambiental, arte e tecnologia: ações educativas de aproveitamento de resíduos sólidos urbanos. 2007. 173 f. Dissertação (Mestrado em Tecnologia) - Universidade Tecnológica Federal do Paraná, 2007. 
PEREIRA, J. N.; MANSUR, C. B.; ALVES, M. A. M. Avaliação da percepção do meio ambiente por alunos de ensino fundamental de duas escolas da rede pública estadual do município de Dourados, Mato Grosso do Sul. In: ENEPE UFGD, 8, 2014. ENEPEX... 2014, 18 f.

REIGOTA, M. O que é educação ambiental. São Paulo: Brasiliense, 2004.

RUSCHMANN, C.B.F. Formação artística e consciência ambiental. Com Scientia, Curitiba, v. 3, n. 3, jan.-jun., 2007.

SARAIVA, V; M.; NASCIMENTO, K. R. P. do; COSTA, R. K. M. da. A prática pedagógica do ensino de educação ambiental nas escolas públicas de João Câmara - RN. Holos, v. 2, n. 24, p. 81-93. 2008.

SILVA, D. M. C. GRILLO, M. A utilização dos jogos educativos como instrumento de educação ambiental: o caso reserva ecológica de Gurjaú - PE. Contrapontos, Itajaí, v. 8, n. 2, p. 229-238, mai.-ago. 2008.

SULEIMAN, M.; ZANCUL, M.C.S. Meio ambiente no ensino de ciências: análise de livros didáticos para os anos finais do ensino fundamental. Revista Eletrônica do Mestrado em Educação Ambiental, v. 28, p. 289-303. 2012.

NÓVOA, A. (Org.). Os professores e a sua formação. Lisboa: Dom Quixote, 1995 